ANNALES

UNIVERSITATIS MARIAE CURIE-SKŁODOWSKA

LUBLIN - POLONIA

VOL. LXX, 1

SECTIO AA

2015

\title{
Influence of the ambient temperature on water and diiodomethane contact angle with quartz surface
}

\author{
Konrad Terpiłowski \\ Department of Interfacial Phenomena, Faculty of Chemistry, \\ Maria Curie-Sklodowska University, Lublin, Poland
}

\begin{abstract}
Wettability of solids is a key phenomenon in many processes. One should mentioned those which accompany us in our everyday life i.e. washing or cementing as well as those applied in industry e.g. flotation of minerals. Value of the contact angles are affected by many factors. One of them is temperature. In this paper monocrystaline quartz was used in the investigations which were carried out in the range $5-50^{\circ} \mathrm{C}$ with the step every $5^{\circ} \mathrm{C}$. As follows the value of the contact angle of both water and diiodomethane changes with the increasing temperature. The change of its value for water is much larger than in case of another liquids of apolar character. Using Chibowski approach the apparent surface free energy was calculated in two ways with and without correction about temperature change of the surface tension. The calculation show difference between both results. Taking into consideration another value of the surface tension should not be neglected even if measurements is taken at a temperature close to $20^{\circ} \mathrm{C}$ which is the standard in one in such measurements
\end{abstract}

\section{INTRODUCTION}

The measuring of the liquid contact angle is difficult and often troublesome. The value of contact angle is affected by some phenomena, one of them in surface roughness $[1,2]$ of the micrometres order has a significant effect on the value of the measured contact angle and should 
be taken into account during measurements. If the surface has hydrophilic properties and is rough, then wettability of this type of surface is describe by Wenzel [3] model. There are also surfaces characterized by a double hierarchical structure of surface roughness [4-7] and they can possess even superhydrophobic properties. Wettability of this type surfaces is described by the Cassie-Baxter [8] model. In 1805 Young [9] proposed a basic description of surface wettability and so far the measurement of such contact angles as those from the Young equation is a problem. One should mention different methods of measuring contact angles $[10,11]$ and the theory of calculating the equilibrium contact angle from advancing and receding angles proposed by Tadmor [12]. Another important but no fully recognized phenomenon is the apparent surface free energy of solids. The litereature reports some approaches to explain this problem $[13,14]$. One of the most frequently used approach is the approach proposed by van Oss-Good-Chaudhury (LWAB) $[15,16]$ based on the acidic components of liquid surface tension. However, this approach has some limitation as for as its applicability on hydrophobic surfaces is concerned. One of the electron-donor or acceptor parameters usually gives a negative value which is contradictory to the generally accepted rules. Another reported in literature approach for determination of apparent surface free energy is that based on the equation of state for solids proposed by Newmann [17]. In this approach surface tension of liquid and advancing contact angles as well as the constant $\beta$ must be used for calculation of apparent surface free energy. The constant $\beta$ which is $0.000125\left(\mathrm{~mJ} / \mathrm{m}^{2}\right)^{-2}$ was determined experimentaly from mesurements of contact angles on the polymer surface. Recently based on the measuremnets of liquids from n-alkanes of large particles on Teflon surface there has been determined the second value of $\beta$ which is $0.00016\left(\mathrm{~mJ} / \mathrm{m}^{2}\right)^{-2}$ close to that determined earlier [18]. Morrison [19] examining the thermodynamic assumption of the equation of state pointed out to drawbacks of this theory. The first one consist in dependence of energy only on chemical potential of liquid neglecting chemical potential of the gas surrounding the droplets. According to Morrison [19] the apparent surface free energy of the same surface determined using various liquids assumes different values because it depends on the interactions between the liquid and the solid surface. Thus application of the same equation for all solids results in gross averaging of the obtained results. Another problem is thermodynamically false assumption that the "sitting" drop is attached by only two parameters: chemical potential of liquid and temperature. With such assumption the number of grades of measuring 
system freedom is one, that is $\gamma=\gamma(T)$. The assumption making apparent surface free energy dependent on so few parameters makes comparison of measurement systems will each other impossible. Jańczuk et al. [20] analysed the equation of state pointing out to its discontinuity in same range.

Another theory which allowed to determine apparent surface free energy is that proposed by Chibowski [21,22]. Having measured the advancing $\theta_{a}$ and receding $\theta_{r}$ contact angles of probe liquids and their surface tension $\gamma_{1}$, the apparent surface free energy $\gamma_{\mathrm{s}}$ has been calculated from the contact angle hysteresis using the following equation:

$$
\gamma_{\mathrm{S}}=\frac{\gamma_{\mathrm{L}}\left(1+\cos \theta_{\mathrm{a}}\right)^{2}}{2+\cos \theta_{\mathrm{r}}+\cos \theta_{\mathrm{a}}}
$$

The main limitation of this theory is making the obtained result dependent on the kind of liquid used for measuring the contact angle.

The other parameters witch have significant effect on contact angle measurements are humidity of the atmosphere in which the measurement proceed $[23,24]$ and temperature. Temperature largely affect the value of measured contact angles because teh liquid surface tension is a function of temperature. Moreover, the components of surface tension determined by Fockes [25] were for the temperature $20^{\circ} \mathrm{C}$. Their application at other temperatures does not make sense. The aim of this paper is finding out how temperature affect for the contact angle of polar and apolar liquids and for apparent surface free energy of well-defined surface as monocrystalic quartz.

\section{EXPERIMENTAL}

\subsection{Quartz surface characteristic}

The quartz plate (alpha quartz, RH, seed less, Institute of Electric Materials Technology Warsaw) was used in the investigations. Before measurement the plate was placed in a vessel with the mixture of chloroform (POCH S.A.) and acetone (POCH S.A.) (1:1) and subject to the ultrasounds bath. After $10 \mathrm{~min}$. the plate was taken out and left for drying. Then it was placed in the chamber for another $20 \mathrm{~min}$. for obtaining the required temperature. On temperature conditioned plate were measured advancing and receding contact angles of water (Milli-Q system), and diiodomethane (Merck 99.5\%) using the micro syringe. 
A)

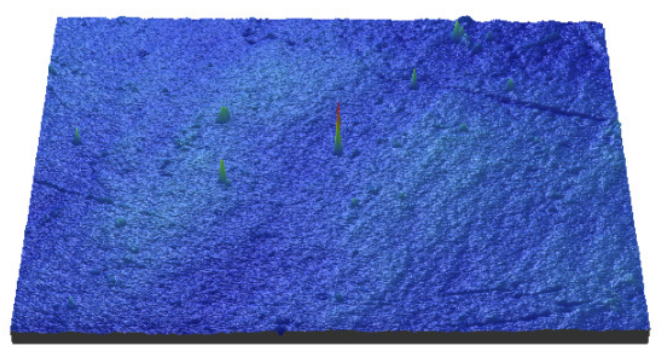

B)

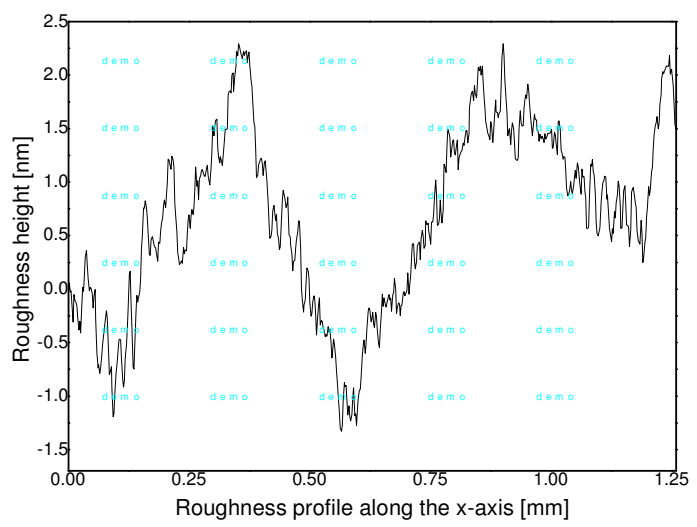

Fig. 1 A) 3D image of quartz plate obtained from optical profilometer $(0.94 \times 1.3 \mathrm{~mm}), \mathrm{B})$ Surface roughness profile along axis X.

Monocrystaline quartz was chosen for investigation due to its relatively smooth surface its average roughness is $R_{a}=0.8 \mathrm{~nm}$ and the average square root from roughness is $R_{R M S}=1.0 \mathrm{~nm}$.

\subsection{Method of contact angle determination}

Contact angle were measured by means of the apparatus produced by GBX France, equipped with a chamber with controlled humidity and temperature in the range $5-95^{\circ} \mathrm{C}$ (thermostat filled with water). The system of heating a syringe with the liquid used for contact angle measurements, composed of glass heating jacket and connected to the thermostat was added to the apparatus. The investigation were carried out from the temperature equal to $5^{\circ} \mathrm{C}$, increasing it by 5 degrees until the final temperature was $50^{\circ} \mathrm{C}$. However, the investigation were not carried out at higher temperatures because of the rate of liquid evaporation from the surface. The results obtained for higher temperatures were characterized by significant standard deviation. 
The quartz plate was placed in the tightly closed chamber in front of the lens of the camera connected with a computer. The drop volume $6 \mu 1$ was measured for each studied liquid by means of a micro syringe mounted over a small table. The mobile arm on which the micro syringe was mounted, was operated using "WinDrop" program with the "downup" function. This made exact location of the drop possible in a desired place on the plate. This program was also used for contact of measuring chamber so that it could be inclined at a suitable angle. The measured drop was gently put on the plate and advancing contact angles were measured from camera picture using the program. Then the micro syringe lowered up to contact to the contact of the needle with the drop and its value was diminished by $2 \mathrm{~mm}^{3}$. Further measurement of the receding contact angles were analogous to the eerier one. About 20 droplets were measured for each temperature on the quartz plate. The obtained results were statistically processed and finally the surface free energy was calculated from about 10 contact angles. The air humidity was $50 \% \mathrm{RH}$ in the process of measurement.

The values of surface tension for water at different temperatures were taken from Mirowska [26] and for diiodomethane calculated form [27] using the equation of straight line.

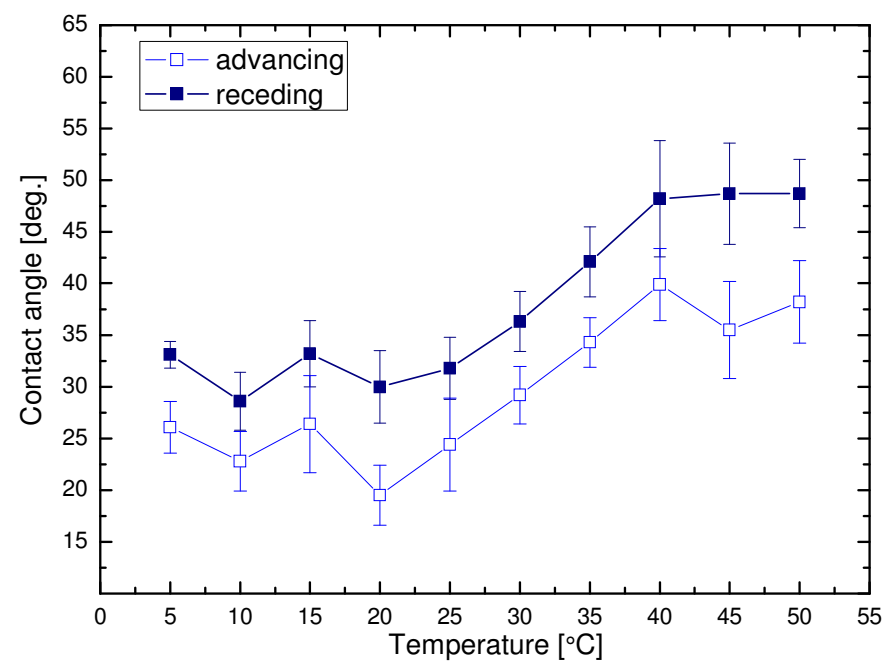

Fig. 2. Water advancing and receding contact angles measured on quartz plates.

As follows from Fig. 2 the values of water advancing and receding contact angles depend on measurement temperature. Advancing contact angles change within $20.1^{\circ}$. The lowest value of advancing contact angle was measured at $10^{\circ} \mathrm{C}$ and it was $28.6 \pm 2.8^{\circ}$ and the highest $48.7 \pm 3.3^{\circ}$ 
was obtained at $50^{\circ} \mathrm{C}$. Changes were also observed for the receding contact angles as a function of temperature. Receding contact angles change within $20.4^{\circ}$. The lowest value of receding contact angle was $19.5 \pm 2.9^{\circ}$ at $20^{\circ} \mathrm{C}$ ant the highest value $39.9 \pm 3.5^{\circ}$ at $40^{\circ} \mathrm{C}$. In the range of low temperatures form $5^{\circ} \mathrm{C}$ to $15^{\circ} \mathrm{C}$ the average water advancing contact angle decreases by $4.5^{\circ}$, then increases by $4.7^{\circ}$. The largest increase of average advancing contact angle by as much as $18.2^{\circ}$ is found from $5^{\circ} \mathrm{C}$ to $40^{\circ} \mathrm{C}$. The curve reaches the quasi plateau in the temperature range $40-50^{\circ} \mathrm{C}$. The same changes are observed for receding contact angle. The receding contact angle changes slightly for low temperature values. The largest increase of the receding angle by $20.4^{\circ}$ is observed in the same range of temperature $\left(20-40^{\circ} \mathrm{C}\right)$ as for the advancing contact angles.

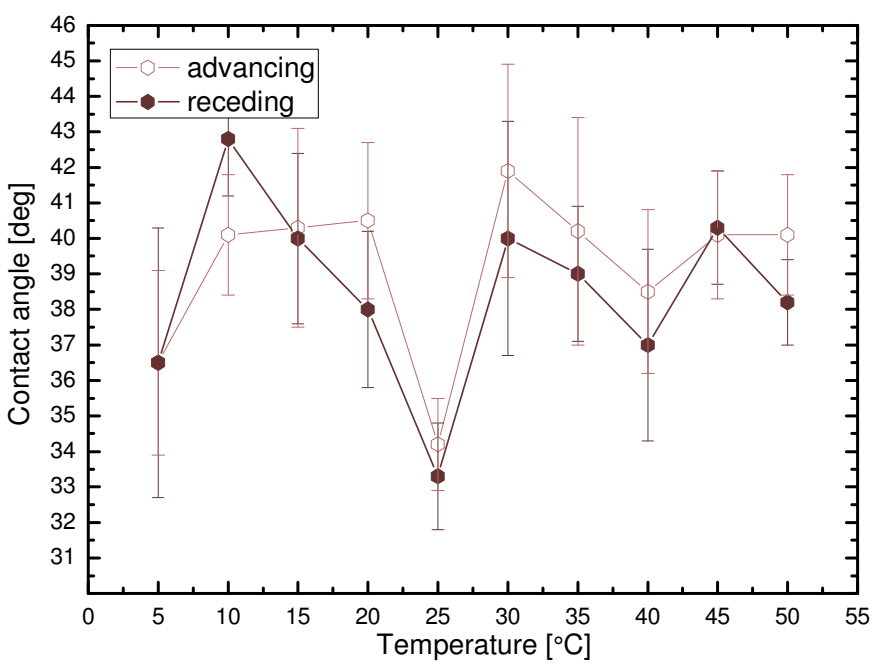

Fig. 3. Diiodomethane advancing and receding contact angles measured on quartz plate.

As follows from Fig. 3 the value of diiodomethane advancing and receding contact angles depends on the measurement temperature. However, the extent of these changes is smaller than from water (Fig. 2). Advancing contact angle change with $9.5^{\circ}$. The loves value of diiodomethane advancing angle was measured in $25^{\circ} \mathrm{C}$ and it was $33.3 \pm 1.5^{\circ}$ but the highest value $42.8 \pm 1.6^{\circ}$ at $10^{\circ} \mathrm{C}$. A similar course of the curve is found for the diiodomethane receding contact angles in the function of temperature. Receding contact angles change within $34.2 \pm 1.3^{\circ}$ at $25^{\circ} \mathrm{C}$ to the highest value $41.9 \pm 3.0^{\circ}$ at $30^{\circ} \mathrm{C}$. At $5^{\circ} \mathrm{C}$ no contact angle hysteresis is observed. 


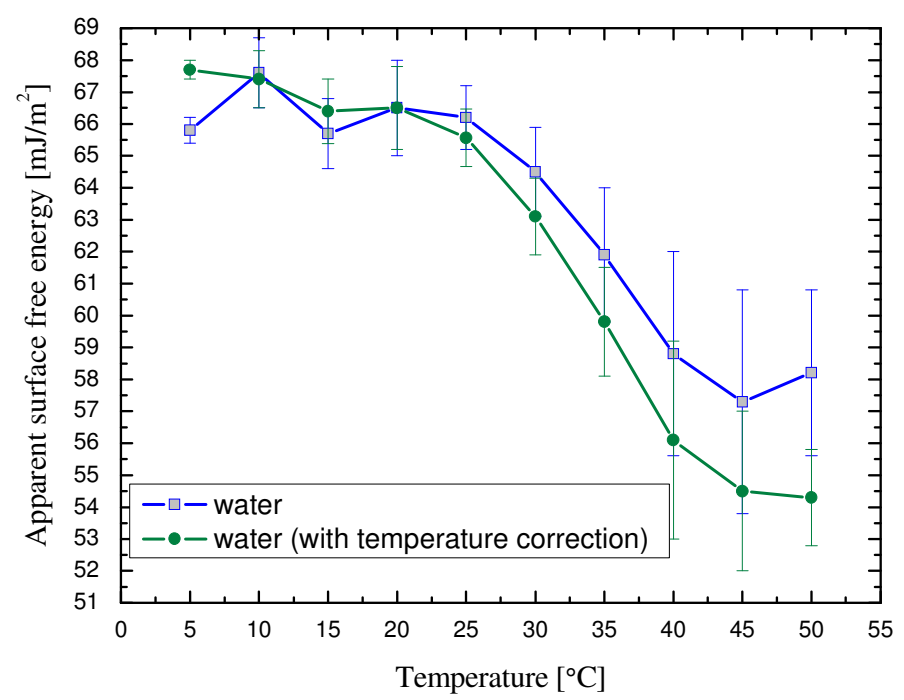

Fig. 4. Apparent surface free energy of quartz surface calculated form hysteresis approach.

As can be seen in Fig. 4 the value of apparent surface free energy decreases with the increasing temperature, when at $10^{\circ} \mathrm{C}$ it is $67.7 \mathrm{~mJ} / \mathrm{m}^{2}$, at $50^{\circ} \mathrm{C}$ it drops up to the value $54.3 \pm 1.5 \mathrm{~mJ} / \mathrm{m}^{2}$ which indicates a significant decrease $10 \mathrm{~mJ} / \mathrm{m}^{2}$. If in calculation of apparent surface free energy, temperature changes of liquid tension are not taken into account, the trend of changes is maintained. However, in the extreme case the difference in value is about $4 \mathrm{~mJ} / \mathrm{m}^{2}$ which results in serious adulteration of the results.

In the case of apolar liquid such as diiodomethane (Fig. 5), the effect on apparent surface free energy is much smaller and the difference between the highest and lowest values is $4 \mathrm{~mJ} / \mathrm{m}^{2}$. The calculation error resulting, from not taking temperature changes of surface tension into account is about $3 \mathrm{~mJ} / \mathrm{m}^{2}$. Comparing the results with the data published in the scientific literature published by Jańczuk at al. [28] and Zdziennicka at al. [29], good compliance of the results in terms of the contact angles and apparent surface free energy can be observed. They used quartz plates obtained from quartz glass cells. The research was carried out at $20^{\circ} \mathrm{C}$ and the water advancing contact was $26.8^{\circ}$ and $26.1^{\circ}$ respectively whereas the diiodomethane advancing contact angle was $36.5^{\circ}$ in both manuscripts. The apparent surface free energy was calculated using the van Oss-Good-Chaudhury (LWAB) method $[15,16]$ and it was aboutl $59.0 \mathrm{~mJ} / \mathrm{m}^{2}$. Suzuki at al. [30] calculated the apparent 
surface free energy for synthetic quarts using the Fowks [31] approximation and it was about $56.0 \mathrm{~mJ} / \mathrm{m}^{2}$. The apparent surface free energy calculated in this paper at $20^{\circ} \mathrm{C}$ was $66.5 \pm 1.5 \mathrm{~mJ} / \mathrm{m}^{2}$ which is about $10 \mathrm{~mJ} / \mathrm{m}^{2}$ higher but it should be mentioned that using the hysteresis approach $[22,23]$ the apparent surface energy is calculated using both advancing and receding contact angles.

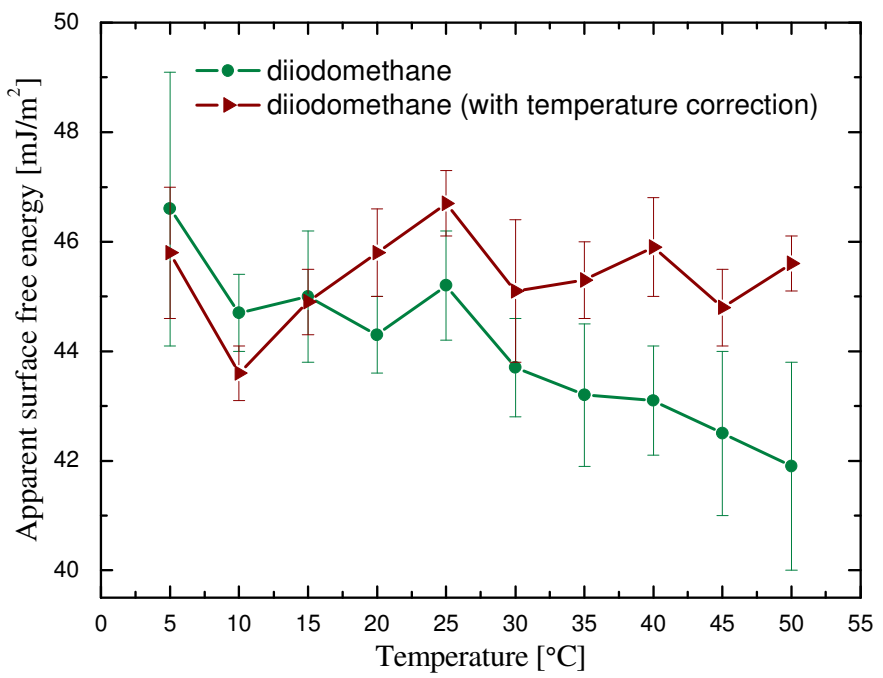

Fig. 5. Apparent surface free energy on the quartz plate calculated from hysteresis approach.

Comparing the obtained results with the literature data, it can be stated that independent of the surface chosen to investigations the increase in water contact angle is observed. Yekta-Fed and Ponter [32] studied the effect of drop size and temperature on the contact angles of water and hydrocarbons on Teflon, copper and stainless steel. Similar to the results presented in the paper the changing temperature had a much larger effect on the value of contact angle of polar liquids than apolar hydrocarbons. Change of the contact angle in the case of copper were believed to be case by its nestling due to the presence of water vapour in both the chamber and adsorbed on the surface. However, after removal of water vapour by washing the chamber with nitrogen and argon, this effect was still present. Thus it was concluded that oxidation of cooper surface has a minimal effect on the contact angles but the changes are due to the tension of film of the liquid accumulated on the surface. Also impurities on the surface or introduced during cleaning can have some influence. Zao et al. [33] studied that effect of temperature on the surface on the 
contact angles of water, diiodomethan, and ethylene glycol on the amorphous film of carbon deposited on stainless steel. Similar to the results presented in this paper they observed a much lower effect of temperature on value of measured contact angles of diiodomethane and water. Remembering that diiodomethane reacts with the surface in a dispersive way, it can be concluded that changing value of the polar component of apparent surface free energy is main factor who is responsible for changes of contact angle and total value of apparent surface free energy. Using the components of liquid surface tension Zao et al. [33] proved that changes in wettability are caused by the increase of electron-acceptor parameter of apparent surface free energy with the increasing temperature. Taking into account the studies by Jańczuk et al. [34] on carbon black and apparent surface free energy determination from heat of immersion, it should be remembered that value of dispersion parameter of apparent surface free energy $\gamma_{\mathrm{s}}^{\mathrm{LW}}$ depends on the interpretation of contribution of film surrounding the droplet and change of contact angle value is affected by the electron-acceptor parameter of the apparent surface free energy and the existence of film adsorbed around the liquid droplet whose contact angles are measured.

Also impurities on the surface or introduced during cleaning can have some influence. Zao et al. [29] studied that effect of temperature on the surface on the contact angles of water, diiodomethan, and ethylene glycol on the amorphous film of carbon deposited on stainless steel. Similar to the results presented in this paper they observed a much lower effect of temperature on value of measured contact angles of diiodomethane and water. Remembering that diiodomethane reacts with the surface in a dispersive way, it can be concluded that changing value of the polar component of apparent surface free energy is main factor who is responsible for changes of contact angle and total value of apparent surface free energy. Using the components of liquid surface tension Zao et al. [29] proved that changes in wettability are caused by the increase of electron-acceptor parameter of apparent surface free energy with the increasing temperature. Taking into account the studies by Jańczuk et al. [30] on carbon black and apparent surface free energy determination from heat of immersion, it should be remembered thet value of dispersion parameter of apparent surface free energy $\gamma_{s}^{L W}$ depends on the interpretation of contribution of film surrounding the droplet and change of contact angle value is affected by the electron-acceptor parameter of the apparent surface free energy and the existence of film adsorbed around the liquid droplet whose contact angles are measured. 


\section{CONCLUSIONS}

Temperature of measurement affects the contact angle and its hysteresis. For the studied surface they change in a characteristic way showing some minima and maxima. The value of measured advancing and receding contact angles depends on the temperature at which measurements were conducted. However, the range of changes for diiodomethane is much smaller compared with that for water. Studies of wettability are usually carried out at $20^{\circ} \mathrm{C}$ but some studies reported in literature do not give temperature of measurement [35] or just state it was room temperature [36]. As proved the temperature even of the order $5^{\circ} \mathrm{C}$ not taken into account in the investigations affects the obtained value of energy significantly. Changes in the wettability of the studies surface are due to the increase of electorn-acceprot parameter combined with the existence of the liquid film adsorbing during measurements.

\section{REFERENCES}

[1] E.L. Decker, B. Frank, Y. Suo, S. Garoff, Colloids Surf. A, 156, 177, (1999).

[2] T. S. Merion, A. Marmur, I. Sam Saguy, J. Colloid Interface Sci. 274, 637, (2004).

[3] R.N. Wenzel., Ind Eng Chem., 28, 98, (1936),

[4] W. Barthlott, C. Neinhuis, Planta 202, 1, (1997).

[5] E. Chibowski, L. Holysz, K. Terpilowski, Colloid Surfaces A, 291, 181, (2006).

[6] J. Drelich, E. Chibowski, D. D. Meng, K. Terpilowski, Soft Matter, 7, 9804, (2011).

[7] L. Hołysz, K. Terpiłowski, E. Chibowski, Surface Innovations 1, 52, (2013).

[8] A.B.D. Cassie, S. Baxter, Trans. Faraday Soc. 40, 546, (1944).

[9] Young T. Philos Trans $R$ Soc, 95, 65, (1805).

[10] D.Y. Kwok, C.J. Budziak, A.W. Neumann, J.Colloid Interface Sci. 173, 143, (1995).

[11] Marmur Contact Angle, Wettability and Adhesion. 6, 3, (2009).

[12] R. Tadmor, Langmuir 20, 7659, (2004).

[13] F. Etzler, Rev. Adhesion Adhesives, 1(1), 3, (2013).

[14] M. Żenkiewicz, Polimery 52(10), 760, (2007). 
[15] C.J. van Oss, R.J. Good, M.K. Chaudhury, Langmuir 4, 884, (1998).

[16] C. J. van Oss, Colloids Surf. A. 78, 1, (1993).

[17] A.W. Neumann, R.J. Good, C.J. Hoppe,M. Sejpal, J. Colloid. Interface Sci., 49, 291, (1974).

[18] H. Tavana, G. Yang, C.M. Yip, D. Appelhans, S. Zschoche, K. Grundke, M.L. Hair, A.W. Neumann, Langmuir 22, 628, (2006).

[19] D. Morrison, Langmuir 5, 540, (1989).

[20] B. Jańczuk, J. M. Bruque, M. L. González-Martín, J. Moreno Del Pozo, A. Zdziennicka, F. Quintana-Gragera, J. Colloid Interface Sci., 181, 108, (1996).

[21] E. Chibowski, in Contact Angle, Wettability and Adhesion, K.L. Mittal, (Ed.), VSP, 2, 2, Uterecht (2002).

[22] E. Chibowski, Adv. Colloid Inter. Sci. 133, 51, (2007).

[23] E. Chibowski, K. Terpiłowski, L. Hołysz, in: Advances in Contact Angle, Wettability and Adhesion, (K.L. Mittal ed.) Scrivener Publishing LLC. 19, 329, (2013).

[24] L. Holysz, E. Chibowski, K. Terpilowski, in Contact Angle, Wettability and Adhesion. 5, 95, (2008).

[25] F.M Fowkes, J. Phys. Chem. 72, 3700, (1968).

[26] N. Mirowska "Materiały pomocnicze do ćwiczeń w LPF" www.if.pwr.wroc.pl/lpf/informacje/mpl.pdf

[27] C. Fan, S.C. Lee, Material Trensportation, 48(9), 2449, (2007).

[28] B. Jańczuk, A. Zdziennicka, Journal of Material Science, 29, 3559, (1994).

[29] Zdziennicka, B. Jańczuk, K. Szymczyk, Journal of Colloid and Interface Science, 340, 243, (2009).

[30] T. Suzuki, N. Sugihara, K. Teshima, S. Oishi, M. Kawasaki, Journal of Crystal Growth, 311, 719, (2009).

[31] F.W. Fowks, Industrial \& Engineering Chemistry Research, 56, 40, (1954).

[32] M. Yekta-Fard, A.B. Ponter, J. Adhesion, 18, 197, (1985).

[33] Q. Zhao, Y. Liu, E.W. Abel, Journal of Colloid and Interface Science, 280, 174, (2004).

[34] M.L. Gonzalez-Martin, B. Jańczuk, L. Labajos-Broncano, J.M. Bruque, Langmuir, 13(22), 5991, (1997).

[35] Z.J. Luan, Y. Wang, F. Wang, L.Y. Huang, L. Meng, Thin Solid Films, 519, 7830, (2011). 
[36] S.P. Thomas, S. Thomas, R. Abraham, S, Bandyopadhyay, Polymer Letteres, 2(7), 528, (2008).

\section{CURRICULUM VITAE}

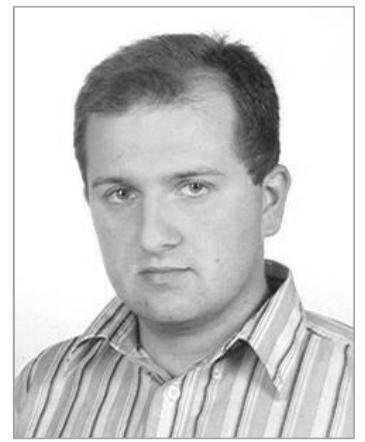

Konrad Terpitowski was born in Poland in 1979. He studied chemistry at Maria Curie Skłodowska University in Lublin and graduated in 2003. At present he is an assistant professor in the Department of Interfacial Phenomena UMCS Lublin. His research work is apparent surface free energy of solids and stability of dispersed systems. 